\title{
PELATIHAN PENGGUNAAN MEDIA SOSIAL UNTUK MENINGKATKAN PEMASARAN PRODUK UMKM PULAU SALAH NAMA
}

\author{
Irma Salamah ${ }^{1 *}$, Raden Kusumanto ${ }^{2}$, A. Rahman ${ }^{2}$, Mohammad Fadhli ${ }^{1}$, \\ Elmerillia $^{1}$, Anisah Meidella ${ }^{1}$ \\ ${ }^{1,}$ Teknik Telekomunikasi, Politeknik Negeri Sriwijaya \\ ${ }^{2}$,Teknik Elektronika, Politeknik Negeri Sriwijaya \\ email:irma.salamah@yahoo.com
}

\begin{abstract}
The Salah Nama island is located in the middle of the Musi River waters, located in Mariana Ilir Village, Banyuasin 1 District, Banyuasin Regency, South Sumatra Province. The people of Salah Nama Island have UMKM engaged in culinary, animal husbandry and agriculture. The current obstacle that is still being faced is the marketing of UMKM products. Coupled with access to locations that are still quite difficult to reach. Lack of promotion due to lack of marketing strategy is a major problem. Globalization that continues to grow is also marked by the number of existing social media. Today, social media has become the center of public attention that can be used as a means of product marketing. The lack of information and knowledge about the use of the internet and social media in the people of Salah Nama Island is one of the causes of the non-optimal use of existing social media. This service program is carried out with the aim of training the community in using social media so that they can increase the marketing of UMKM products on Salah Nama Island. The method used is by conducting counseling, practical assistance, to discussion. From the stages of service that have been carried out, the community understands how to create social media accounts and understands the use of social media in various aspects, not only as a means of communication. So that people can use social media to improve the economy.
\end{abstract}

Keywords: marketing; micro small medium enterprises; salah nama island; social media

Abstrak: Pulau salah nama berada di tengah perairan Sungai Musi, berlokasi di Kelurahan Mariana Ilir, Kecamatan Banyuasin 1, Kabupaten Banyuasin, Propinsi Sumatera Selatan. Masyarakat Pulau Salah Nama memiliki UMKM yang bergerak dibidang kuliner, peternakan dan pertanian. Kendala saat ini yang masih dihadapi ialah bidang pemasaran produk UMKM. Ditambah dengan akses lokasi yang masih cukup sulit dijangkau. Kurangnya promosi akibat minimnya strategi pemasaran menjadi permasalahan utama. Globalisasi yang terus berkembang juga ditandai dengan banyaknya media sosial yang ada. Dewasa ini media sosial menjadi pusat perhatian publik yang dapat dimanfaatkan untuk menjadi sarana pemasaran produk. Minimnya informasi dan pengetahuan mengenai penggunaan internet dan media sosial pada masyarakat Pulau Salah Nama menjadi salah satu penyebab belum optimalnya penggunaan media sosial yang ada. Program pengabdian ini dilaksanakan dengan tujuan untuk melatih masyarakat dalam menggunaan media sosial sehingga dapat meningkatkan pemasaran produk UMKM di Pulau Salah Nama. Metode yang digunakan yaitu dengan melakukan penyuluhan, pendampingan praktik, hingga diskusi. Dari tahapan pengabdian yang sudah dilaksanakan masyarakat menjadi paham cara pembuatan akun media sosial dan mengerti kegunaan media sosial dalam berbagai aspek tidak hanya sebagai sarana komunikasi. Sehingga masyarakat dapat memanfaatkan media sosial untuk meningkatkan perekonomian.

Kata kunci: media sosial; pemasaran; pulau salah nama; usaha mikro kecil menengah 
Available online at https://jurnal.stmikroyal.ac.id/index.php/jurdimas

\section{PENDAHULUAN}

Diera digital ini, internet menjadi satu kebutuhan wajib yang perlu dimiliki setiap individu. Sebagian besar kegiatan diseluruh sektor membutuhkan internet. Tak terkecuali sektor ekonomi, yang memanfaatkan internet sebagai media pemasaran guna memperkenalan produk barang ataupun jasa. Internet sebagai media pemasaran online memberikan dampak yang besar terhadap peningkatan laba usaha dalam sisi finansial (Setiawati, 2017). Pelaku usaha mikro kecil menengah (UMKM) menjadi salah satu contoh pengguna internet dibidang ekonomi.

Usaha Mikro Kecil Menengah menjasi salah satu factor penting dalam pertumbuhan ekonomi (Harini, \& Handayani, 2006). Pengembangan usaha mikro kecil menengah (UMKM) merupakan salah satu cara yang dapat dilakukan untuk menanggulangi kemiskinan. Pengembangan UMKM memberikan kontribusi yang besar dalam penyerapan tenaga kerja, yakni sebesar 99,45\% dan 30\% terhadap PDB (Suci, 2017). Upaya peningkatan UMKM juga turut aktif dilakukan oleh mahasiswa Politeknik Negeri Sriwijaya dengan menjadikan masyarakat Pulau Salah Nama menjadi mitra usaha. Pulau Salah Nama berlokasi di Kelurahan Mariana Ilir, Kecamatan Banyuasin I, kabupaten Banyuasin.

Melalui program wirausaha yang ada, masyarakat mulai mengembangkan diri dengan memiliki beberapa usaha diberbagai bidang: kuliner, peternakan, dan pertanian. Namun, kendala yang saat ini dihadapi masyarakat dalam menjalankan usaha ialah pemasaran. Penyebabnya karena akses lokasi yang cukup sulit dijangkau, informasi produk yang belum begitu menyebar, dan teknik pemasaran yang masih minim. Padahal sistem promosi produk menjadi usaha penting dalam menarik minat konsumen (Poetra \& Christantyawati, 2017).

Kondisi lokasi yang memiliki akses khusus menjadi tantangan bagi masyarakat sekitar untuk dapat dengan mudah dan cepat berinteraksi dengan masyarakat daerah lain di sekitarnya. Adanya akses internet yang sudah baik menjadi salah satu fasilitas yang dapat dioptimalkan masyarakat setempat. Disamping itu, sebagian besar masyarakat sudah memiliki handphone yang dapat digunakan untuk mengakses internet dan media sosial.

Dewasa ini era jejaring sosial telah mengubah paradigma pemasaran ke pemasaran modern (online) dari pemasaran tradisional (offline) (Vernia, 2017). Berdasarkan (Puspitarini \& Nuraeni, 2019), Youtube, Facebook, Instagram, dan Twitter menjadi media sosial yang diminati orang Indonesia. Banyaknya media sosial yang ada menambah peluang lokasi dan teknik pemasaran

Media sosial memiliki peran yang sangat penting sebagai tempat menjual produk yaitu meningkatkan penjualan secara online (Manik Pratiwi, 2020). Komunikasi pemasaran melalui media sosial bertujuan menumbuhkan minat beli konsumen (Indika \& Jovita, 2017). Namun, kurangnya pengetahuan dan pendampingan bagi masyarakat menyebabkan minimnya pemanfaatan teknologi yang ada. Masyarakat Pulau Salah Nama belum memahami kegunaan media sosial sebagai upaya peningkatan pemasaran produk UMKM. Selain itu juga belum memahami tahapan pembuatan akun media sosial dimulai dari pembuatan email, facebook, dan instagram.

Masyarakat belum mengetahui dan menerapkan cara yang baik dan benar dalam melakukan pemasaran 
Available online at https://jurnal.stmikroyal.ac.id/index.php/jurdimas

produk UMKM melalui media sosial. Sehingga perlu dilakukan pelatihan penggunaan media sosial untuk meningkatkan pemasaran produk UMKM Pulau Salah Nama.

Menurut (Fuadi, Akhyadi, \& Saripah, 2021), keterlibatan pelaku UMKM menjadi peran utama dalam proses pendampingan untuk meningkatkan digitalisasi eko-nomi. Dengan diadakannya pelatihan ini masyarakat dapat manfaatkan media sosial sebagai media pemasaran produk UMKM, masyarakat juga dapat membuat dan memiliki akun media sosial.

\section{METODE}

Kegiatan pengabdian masyarakat ini dilaksanakan di Pulau Salah Nama yang beralamat di RT. 01 RW.01, Kelurahan Mariana Ilir, kecamatan Banyuasin 1, kabupaten Banyuasin. Kegiatan ini diikuti oleh 20 orang masyarakat Pulau Salah Nama yang didominasi memiliki UMKM diberbagai bidang, diantaranya kuliner, peternakan, dan pertanian. Pelatihan dilaksanakan di rumah ketua rukun tetangga 01, Pulau Salah Nama pada tanggal 16 Maret 2021. Pelaksanaan kegiatan pengabdian masyarakat dilakukan dengan tiga tahapan yaitu penyuluhan, pendampingan praktik, dan diskusi.

\section{Penyuluhan}

Pada Tahapan ini dilakukan pemberian materi secara lisan dan menampilkan materi pada power point agar lebih mudah dipahami. Adapun materi yang diberikan mengenai dasar - dasar internet, mulai dari pengertian maupun langkahlangkah mengakses internet, fungsi internet, dan tips penggunaan internet. Selanjutnya dilakukan pelatihan pembuatan electronic mail (e-mail) sebagai langkah awal dalam pembuatan akun media sosial yaitu facebook dan instagram. Kemudian pemberian pelatihan pembuatan Facebook dan Instagram.

\section{Pendampingan Praktik}

Setelah pemberian penyuluhan, masyarakat langsung mempraktikkan langkah mengakses internet, mulai dari membuka browser, membuat e-mail, dan membuat akun facebook dan instagram. Masyarakat melakukan praktik dengan menggunakan handphone masing-masing dan untuk masyarakat yang tidak memiliki handphone diberikan fasilitas peminjaman handphone oleh tim pengabdi. Dalam tahapan ini tim pengabdi memberikan pendampingan bila peserta masih mengalami kesulitan.

\section{Diskusi}

Tahapan terakhir yang dilakukan ialah tanya jawab. Pada tahap ini masyarakat juga diberikan kesempatan untuk bertanya. Sehingga melalui tahapan ini tim pengabdi dapat mengetahui sejauh mana pemahaman yang didapat masyarakat Pulau Salah Nama dari kegiatan yang telat dilaksanakan.

\section{PEMBAHASAN}

Internet merupakan tema yang diangkat dalam pengabdian ini memfokuskan kepada masyarakat agar dapat mengenal dunia internet sebagai sumber informasi. Jumlah peserta pengabdian sebanyak dua puluh orang yang dikumpulkan dalam satu tempat. Sebagian besar masih awam dalam memahami penggunaan internet sebagai sumber informasi maupun komunikasi. Ada beberapa yang tidak memahami dalam penggunaan handphone. Umumnya 
Available online at https://jurnal.stmikroyal.ac.id/index.php/jurdimas

pengenalan teknologi biasanya hanya mengenalkan alat komunikasi saja seperti handphone tidak dalam penggunaan yang lebih canggih. Ketika melaksanakan pengabdian tim pengabdi terlebih dahulu memberikan lembaran berupa pertanyaan seputar internet agar tim pengabdi mengetahui batasan pehamanan masyarakat dalam mengenal internet.

Tahapan selanjutnya tim pengabdi menyiapkan bahan ajar untuk diberikan kepada masyarakat pulau salah nama secara lisan dalam bentuk gambar yang ditampilkan pada proyektor sebagai fasilitas dari tim pengabdi. Adanya pengabdian ini diharapkan masyarakat lebih memahami dunia internet dan cara memanfaatkannya sebagai sumber informasi maupun pemasaran produk UMKM yang dibuat oleh masyarakat Pulau Salah Nama. Setelah diberikannya bahan ajar oleh tim pengabdi, masyarakat melakukan praktik secara mandiri untuk penggunaan internet terkhususnya dalam pembuatan media sosial sebagai sarana informasi dan komunikasi yang berperan penting bagi masyarakat saat ini. Materi yang disampaikan oleh tim pengabdi merupakan pengertian penggunaan internet dan macam-macam media sosial yaitu $e$-mail, Instagram dan facebook.

Dan juga tim pengabdi melakukan praktik terhadap masyarakat dalam pembuatan akun media sosial yang sudah disebutkan sebelumnya dengan cara didampingi satu per satu oleh tim pengabdi setelah dijelaskan pada waktu tim pengabdi melisankan materi. Media sosial merupakan suatu media komunikasi jarak jauh untuk bersosialisasi satu sama lain.

Pada tahap praktik pembuatan akun media sosial tim pengabdi melihat adanya keterbatasan dalam alat komunikasi dan banyaknya masyarakat yang belum memiliki akun media sosial terse- but, maka dari itu tim pengabdi memberikan fasilitas peminjaman handphone untuk masyarakat yang tidak memiliki agar dapat mencoba membuat akun media sosial secara mandiri dan didampingi tim pengabdi. Sebagian besar masyarakat masih asing dengan bahasa dan tampilan media sosial yang digunakan pada saat melakukan pembuatan akun yang kurang dimengerti dikarenakan masyarakat tidak terbiasa melihat tampilan pada media sosial yang sudah sangat canggih. Penggunaan internet pada masyarakat pulau salah nama sangat membantu dalam mengembangkan UMKM untuk pemasaran produk yang saat ini sangat marak menggunakan dunia internet terkhususnya dengan bantuan media sosial.

Ketika proses pengabdian berlangsung masyarakat Pulau Salah Nama dengan baiknya banyak menanyakan perihal penjelasan materi yang kurang mereka pahami agar diminta menjelaskan ulang secara bertahap kepada tim pengabdi. Berdasarkan praktik yang dilakukan kepada masyarakat dalam pembuatan akun media sosial, masyarakat sangat senang dan antusias agar dapat membuat akun dengan sendiri untuk kedepannya dan menerapkan teknologi untuk mengembangkan dan mendapatkan informasi dari berbagai kalangan. Hasil yang didapatkan selama proses pengabdian masyarakat telah memahami adanya internet dan penggunaan internet bahkan sampai pembuatan akun media sosial.

Dari kegiatan ini masyarakat telah memahami penggunaan internet sebagai sumber informasi dan komunikasi. Selain memahami apa kegunaan internet, didapatkan juga hasil dalam pembuatan akun yang sudah dimengerti masyarakat yang awam akan dunia internet. Diharapkan juga dengan adanya pengabdian ini 
masyarakat tidak asing lagi dengan internet dan media sosial agar lebih mudah dalam mengakses infromasi dari luar dan memberikan informasi. Melalui kegiatan pengabdian ini, masyarakat mendapatkan pengetahuan baru mengenai kegunaan internet dalam peningkatan pemasaran UMKM yang dimiliki. Disamping itu masyarakat juga telah memahami langkah yang dapat dilakukan untuk melakukan pemasaran produk UMKM dimedia sosial.

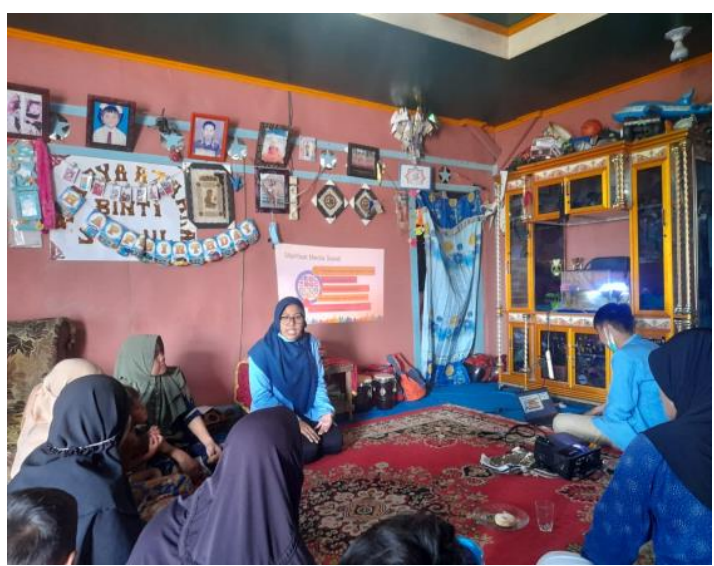

Gambar 1. Foto pemaparan materi oleh tim pengabdi

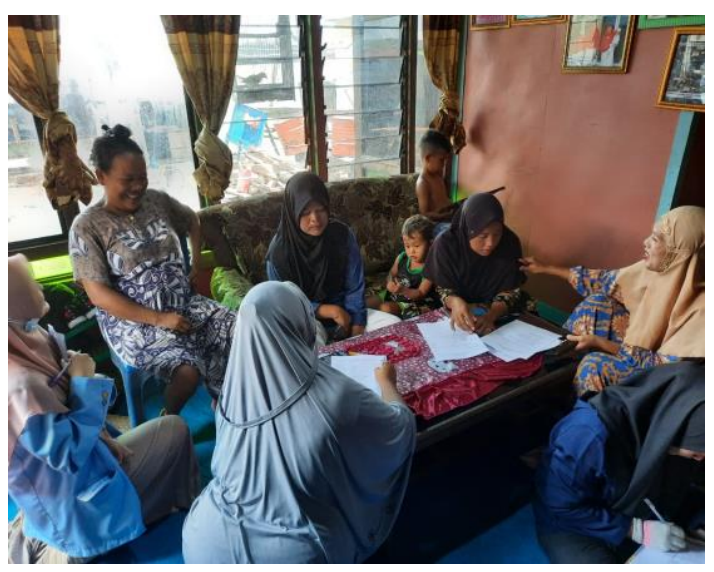

Gambar 2 . Pengisian data oleh masyarakat

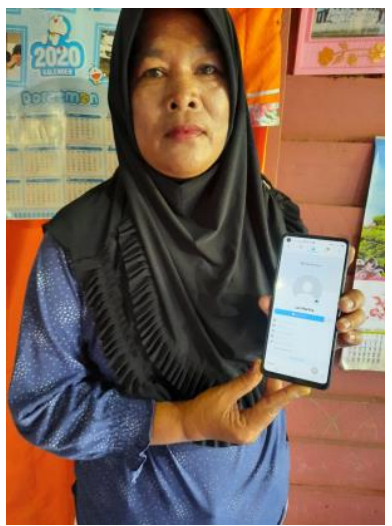

Gambar 3. Foto hasil pembuatan akun media sosial

\section{SIMPULAN}

Setelah diadakannya sosialisasi dan pelatihan secara teori maupun praktek mengenai penggunaan media sosial di Pulau Salah Nama Dengan demikian, masyarakat lebih mengenal kegunaan media sosial tekhusus sebagai upaya peningkatan pemasaran produk UMKM. Masyarakat juga memahami tahapan dalam pembuatan akun media sosial: facebook dan Instagram. Disamping itu masyarakat jadi mengetahui tips mengenai cara yang baik dan benar dalam melakukan pemasaran produk UMKM melalui media sosial.

\section{UCAPAN TERIMA KASIH}

Ucapan terima kasih sampaikan kepada Ketua Rukun Tetangga dan masyarakat Pulau Salah Nama atas kerja sama dan dukungannya dalam penyelenggaraan kegiatan Pelatihan Penggunaan Media Sosial Untuk Meningkatkan Pemasaran Produk UMKM Pulau Salah Nama. 


\section{DAFTAR PUSTAKA}

Fuadi, D. S., Akhyadi, A. S., \& Saripah, I. (2021). Systematic Review: Strategi Pemberdayaan Pelaku UMKM Menuju Ekonomi Digital Melalui Aksi Sosial. Diklus: Jurnal Pendidikan Luar Sekolah, 5(1), 1-13. https://doi.org/10.21831/diklus.v $5 \mathrm{i} 1.37122$

Harini, C., \& Handayani, S. B. (2019). Pemasaran Kewirausahaan Melalui E-Commerce untuk Meningkatkan Kinerja UMKM. Derivatif: Jurnal Manajemen, 13(2).

Indika, D. R., \& Jovita, C. (2017). Media Sosial Instagram Sebagai Sarana Promosi Untuk Meningkatkan Minat Beli Konsumen. Jurnal Bisnis Terapan, 1(01), 25-32. https://doi.org/10.24123/jbt.v1i0 1.296

Manik Pratiwi, A. A. (2020). Peran Media Sosial Dalam Meningkatkan Penjualan Online Saat Pandemi Covid-19. Jurnal Ilmiah Satyagraha, 3(2), 73-81. https://doi.org/10.47532/jis.v3i2. 179

Poetra, R. R., \& Christantyawati, N. (2017). Model AIDA: Pola Penggunaan Media Sosial dalam
Meningkatkan Kepuasan Penjualan di Toko Online Goldies Hijab. Jurnal Komunikasi Profesional, 1(1), 22-36. https://doi.org/10.25139/jkp.v1i 1.170

Puspitarini, D. S., \& Nuraeni, R. (2019). Pemanfaatan Media Sosial Sebagai Media Promosi (Studi Deskriptif pada Happy Go Lucky House). Jurnal Common, 3(1), 71-80.

Setiawati, I. (2017). Pengaruh Strategi Pemasaran Online Terhadap Peningkatan Laba Umkm. Strategi Komunikasi Pemasaran, (20), 1-5. Retrieved from file:///C:/Users/BAYU/Downloa ds/Documents/263-760-1PB.pdf

Suci, Y. R. (2017). Perkembangan UMKM (Usaha Mikro Kecil Menengah) di Indonesia. Jurnal Ilmiah Fakultasi Ekonomi, 6(1), 51-58.

Vernia, D. M. (2017). Optimalisasi Media Sosial Sebagai Sarana Promosi Bisnis Online Bagi Ibu Rumah Tangga Untuk. Jurnal ISBN 978-602-50181-0-7, 1(2), 105-118. Retrieved from http://journal.stkipnurulhuda.ac.i d/index.php/utility/article/view/7 1. 